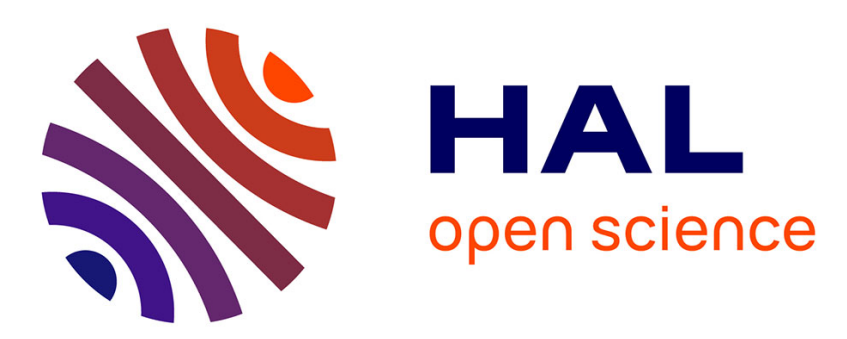

\title{
Converter Nonlinear Fuzzy Control of PMSG-Based for Wind Energy System in Network Context
}

\author{
Elkhatib Kamal, Bogdan Marinescu
}

\section{To cite this version:}

Elkhatib Kamal, Bogdan Marinescu. Converter Nonlinear Fuzzy Control of PMSG-Based for Wind Energy System in Network Context. 2019 IEEE PES Innovative Smart Grid Technologies Europe (ISGT-Europe), IEEE, Sep 2019, Bucharest, Romania. 10.1109/ISGTEurope.2019.8905756 . hal02513262

\section{HAL Id: hal-02513262 \\ https://hal.science/hal-02513262}

Submitted on 20 Mar 2020

HAL is a multi-disciplinary open access archive for the deposit and dissemination of scientific research documents, whether they are published or not. The documents may come from teaching and research institutions in France or abroad, or from public or private research centers.
L'archive ouverte pluridisciplinaire HAL, est destinée au dépôt et à la diffusion de documents scientifiques de niveau recherche, publiés ou non, émanant des établissements d'enseignement et de recherche français ou étrangers, des laboratoires publics ou privés. 


\title{
Converter Nonlinear Fuzzy Control of PMSG-Based for Wind Energy System in Network Context
}

\author{
Elkhatib Kamal and Bogdan Marinescu
}

\begin{abstract}
In this paper, a control of the grid-connected Permanent Magnet Synchronous Generator (PMSG) based on variable speed wind system, taking into account network parameters and the interaction of the wind system with the network is presented. The controlled variables are the speed of the machine and the DC voltage. The proposed Converter Nonlinear Fuzzy Controller (CNFC) is based on a Takagi-Sugeno (TS) fuzzy model and on a control model which allows the electrical system to which the PMSG is connected to be taken into account. Some sufficient conditions for robust stabilization of the TS fuzzy model were derived and have been formulated using a Linear Matrix Inequalities (LMI) format. Obtained performances have been compared with those obtained with Linear Quadratic method (LQ). The control model is a simplified model of the whole system performances which captures the dynamics that are important for the synthesis of the CNFC. The proposed controller methodology is finally demonstrated through the proposed model to illustrate the effectiveness of the proposed method.
\end{abstract}

Index Terms-PMSG; fuzzy controller; LMIs; wind energy systems; grid fault condition.

\section{INTRODUCTION}

A WIND turbine is a machine that converts the kinetic energy of the wind into mechanical energy of the wind type. This mechanical wind energy was initially used to pump water or grind grain. Current machines are used to produce wind power, which is intended for local consumption (isolated sites) or for injection into the electricity grid (gridconnected wind turbines). The "grid connected" or "large wind" application represents, in terms of installed capacity, almost the entire wind power market. Wind energy is now the main source of electricity production from renewable sources (other than nuclear), and plays a key role in many countries, both in the short and long term [1], [2]. Wind energy systems based on Permanent Magnet Synchronous Generator (PMSG) and Doubly Fed Induction Generator (DFIG) have been widely studied in recent years. Most of these studies concerned systems connected to a grid connected to a voltage source, neglecting their interactions with the electricity grid. However, with the increasing penetration of wind power in certain electricity grids, the behaviour of wind power systems towards

E. Kamal and B. Marinescu are with ECN (Ecole Centrale Nantes)- LS2N (Laboratoire des sciences du numérique de Nantes)-DSG (team Dynamics of Smart Grids), 1, rue de la Noë, 44000 Nantes Cedex 3, France, Email: Elkhatib.ibrahim@ec-nantes.fr and Bogdan.Marinescu@ec-nantes.fr.

This project is supported by the WEAMEC (WEst Atlantic Marine Energy Community) for federates the Marine Renewable Energy ecosystem of "Pays de la Loire" French Region in the fields of Research,Training and Innovation activities, through COMEOL project, (see https://www.weamec.fr/blog/record_project/comeol/). This project received also the support of Ecole Centrale Nantes -LS2N (Laboratoire des sciences du numérique de Nantes). the grid and their interaction with it is less and less negligible, leading to specifications required for an increasingly complex and severe connection [2]-[8]. Several classes of network needs can be identified, among which we mention the most appropriate in relation to our approach:

- Voltage withstand in the event of a grid failure: historically, wind turbines were connected to the distribution networks. As machines are grouped into increasingly large wind farms, their direct connection to the very high voltage (VHV) grid is more and more common. This has led to an increase in the voltage with stand voltage requirements in the event of a grid failure, which are now similar to those imposed on conventional power plants (using synchronous machines) with large installed capacity.

- Coverage of a sufficiently wide operating point range: the performance of the machines is linked to the operating point for which their controls are designed. The range of operating points is very wide; this is due, on the one hand, to the great variation in wind speed and, on the other hand, to the changes that occur on the network side (variations in load, changes in topology, etc.).

- In order to properly address these issues, the machine must be considered part of a dynamic system that includes other machines, transmission lines and loads.

The PMSG-based wind power system has been extensively studied [4]-[8]. The Takagi-Sugeno (TS) fuzzy model [9][14] is an appropriate model for approximating a general class of non-linear systems [88]. This type of model is, like Mamdani's, built from a "If...Then" rule base in which the premise is expressed linguistically, but the consequence uses numerical variables rather than linguistic variables.

In this paper, we have analyzed the behavior of PMSG with its converters in a network context. We studied the impact of grid situations on the behaviour of the PMSG-based variable speed wind system [15]-[17]. We have shown how grid influence can be taken into account with a simplified control model including the wind system connected to an infinite node. We have proposed a new coordinated control for the 2 converters of the PMSG that takes into account the network parameters via this control model. This command is based on the Converter Nonlinear Fuzzy Controller (CNFC). We compared this new control strategy with more traditional controls such as vector control and Linear Quadratic (LQ) control in [16]. The performance of the new control system is evaluated in particular in terms of setpoint monitoring and robustness against variations in the length of the network 


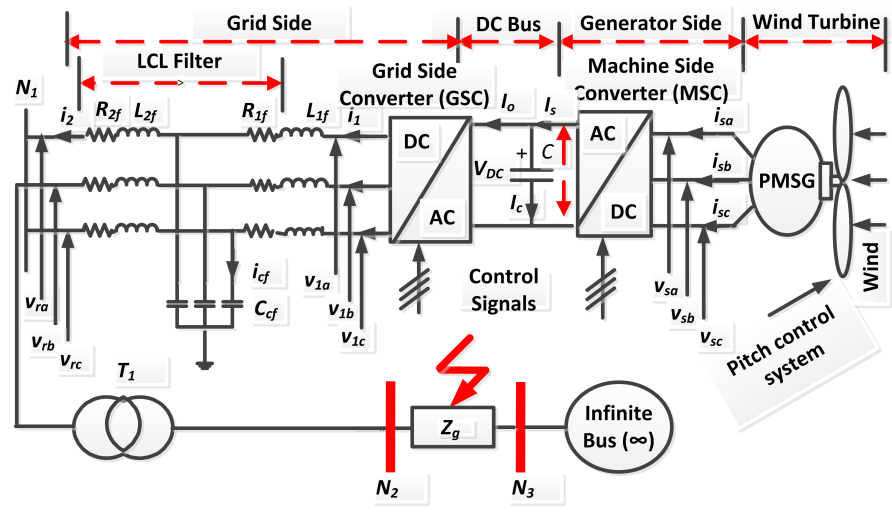

Fig. 1. Structure of the PMSG-WES.

line. We presented a modal analysis of the variable speed wind system based on open-loop and closed-loop PMSG. To summarize we can cite the main benefits of our work as follows: i) a new global approach for the control of a variable speed wind system based on PMSG; ii) Tthe two back to back converters are controlled in a coordinated manner and this allows for better operation in the event of a network failure; iii) The network parameters in which the PMSG is connected are taken into account for the controller synthesis; (iv) Fault Ride-Through Capability (FRT) capability is improved and validated by CNFC; (v) It is stable over a much wider range of grid impedance more than 10 times compared with linear quadratic method (LQ) in [16] at the same grid fault conditions test.

The paper is organised as follows: Section II presents the system dynamic modeling and control model of a PMSG-WES in a grid context. The converter nonlinear fuzzy controller and control analysis are given in Section III. Section IV shows the simulation studies to verify the performance of the proposed method. Finally, conclusions are given in section V.

\section{System Dynamic And Control Model}

The test system is the one shown in Fig. 1 and is used to study the behaviour of wind power systems with PMSG connected to a power system. On the one hand, this test system is small in size to allow direct analysis and, on the other hand, it reproduces a realistic situation of a power system: the PMSG is connected to a transmission network via a block transformer $T_{1}$. The modelling of the transmission network by connected lines certainly remains simplified compared to a real situation but nevertheless makes it possible to take into account the lines of transmission. To analyze the stability of our system, a short circuit is applied in the middle of one of the lines between nodes $N_{2}$ and $N_{3}$ as shown in Fig. 1 .

\section{A. Control Model Analytic Description and Grid Connection}

In this paper, the parameters of the transmission lines are the impedance is given by $Z_{g}=R_{g}+j X_{g}$. The line transmission resistance is often neglected $\left(R_{g}\right.$ of $\left.Z_{g}\right)$ because it is small in relation to its reactance in case of overhead transmission lines [17]-[19].

$$
Z_{g}=X_{g}=j \omega_{g} L_{g}, \quad L_{g}=L l
$$

where, $l$ and $L$ are the line of length and inductance, respectively. The grid voltage $\left(v_{r d}, v_{r q}\right.$ and $\left.v_{r}\right)$ are given by

$$
v_{r d}=V+Z_{g} i_{2 q}, \quad v_{r q}=Z_{g} i_{2 d} \quad v_{r}=\sqrt{v_{r d}^{2}+v_{r q}^{2}}
$$

where $V=1$ for infinite bus $(\infty)$.

\section{B. Nonlinear PMSG-WES Control Model}

The complete model for grid connected PMSG-WES with the line transmission can be described by a ten-order dynamic model which in the compact non-linear affine form may be written in $d-q$ reference frame as

$$
\begin{aligned}
& \frac{d i_{1 d}}{d t}=-\frac{R_{1 f} i_{1 d}}{L_{1 f}}+\omega_{f} i_{1 q}-\frac{v_{c d}}{L_{1 f}}+\frac{U_{1 d}}{L_{1 f}} \\
& \frac{d i_{1 q}}{d t}=-\frac{R_{1 f} i_{1 q}}{L_{1 f}}-\omega_{f} i_{1 d}-\frac{v_{c q}}{L_{1 f}}+\frac{U_{1 q}}{L_{1 f}} \\
& \frac{d i_{2 d}}{d t}=-\frac{R_{2 f} i_{2 d}}{L_{2 f}}+\left(\omega_{f}-\frac{Z_{g}}{L_{2 f}}\right) i_{2 q}+\frac{v_{c d}}{L_{2 f}}-\frac{V}{L_{2 f}} \\
& \frac{d i_{2 q}}{d t}=-\left(\omega_{f}+\frac{Z_{g}}{L_{2 f}}\right) i_{2 d}-\frac{R_{2 f} i_{2 q}}{L_{2 f}}+\frac{v_{c q}}{L_{2 f}} \\
& \frac{d v_{c f d}}{d t}=\frac{i_{1 d}}{C_{f}}-\frac{i_{2 d}}{C_{f}}+\omega_{f} v_{c f q} \\
& \frac{d v_{c f q}}{d t}=\frac{i_{1 q}}{C_{f}}-\frac{i_{2 d}}{C_{f}}-\omega_{f} v_{c f d} \\
& \frac{d i_{s d}}{d t}=-\frac{R_{s} i_{s d}}{L_{s}}+p \Omega i_{s q}+\frac{U_{2 d}}{L_{s}} \\
& \frac{d i_{s q}}{d t}=-\frac{R_{s} i_{s q}}{L_{s}}-p \Omega i_{s d}-\frac{p \Psi}{L_{s}}+\frac{U_{2 q}}{L_{s}} \\
& \frac{d V_{D C}}{d t}=\frac{3}{2 C} \frac{U_{2 d}}{V_{D C}} i_{s d}+\frac{3}{2 C} \frac{U_{2 q}}{V_{D C}} i_{s q}-\frac{3}{2 C} \frac{U_{1 d}}{V_{D C}} i_{1 d} \\
& \quad-\frac{3}{2 C} \frac{U_{1 q}}{V_{D} C} i_{1 q} \\
& \frac{d \Omega}{d t}=\frac{T_{e m}}{J}-\frac{T_{m}}{J}-\frac{f \Omega}{J}
\end{aligned}
$$

where the voltages across the grid $L C L$-filter are balanced (cf. Fig. 1), in addition, $i_{1 d}$ and $i_{1 q}$ are the inverter-side current, $i_{2 d}$ and $i_{2 q}$ are the grid-side current, $v_{c f d}$ and $v_{c f q}$ are the capacitor voltage, $U_{1 d}, U_{1 q}, U_{2 d}$ and $U_{2 q}$ are the inverter output voltage, and $\omega_{f}$ is the angular frequency of the grid voltage, $R_{1}$ and $R_{2}, L_{1}$ and $L_{2}$ and $C_{f}$ are the $L C L$ filter resistances, inductances and capacitance, respectively, $R_{s}$ is the stator winding resistance, $i_{s d}, i_{s q}$ are the $d-q$ components of stator currents, $V_{D C}$ is the output DC side voltage, $J$ and $f$ are the moment of inertia and the friction coefficient, respectively, $T_{e m}$ is the electromagnetic torque which is given by $T_{e m}=p \Psi_{f} i_{s q}$, when the stator $d$ and $q$-axis inductances are equal $\left(L_{s d}=L_{s q}=L_{s}\right), p$ is the number of pole pairs, $\Psi_{f}$ is the magnetic flux, $T_{m}$ is the mechanical torque and $C$ is the DC-Link capacitor.

\section{TS FuZZy CONTROL MOdel AND CONVETRER NONLINEAR FUZZY CONTROLLER}

In this section, TS fuzzy plant model for PMSG-WES is given to design the CNFC as shown in Fig. 2.

\section{A. TS fuzzy Control Model}

The fuzzy dynamic model proposed by TS fuzzy model is often used to represent a nonlinear PMSG-WES system. The global TS fuzzy mode is given by [18]: 


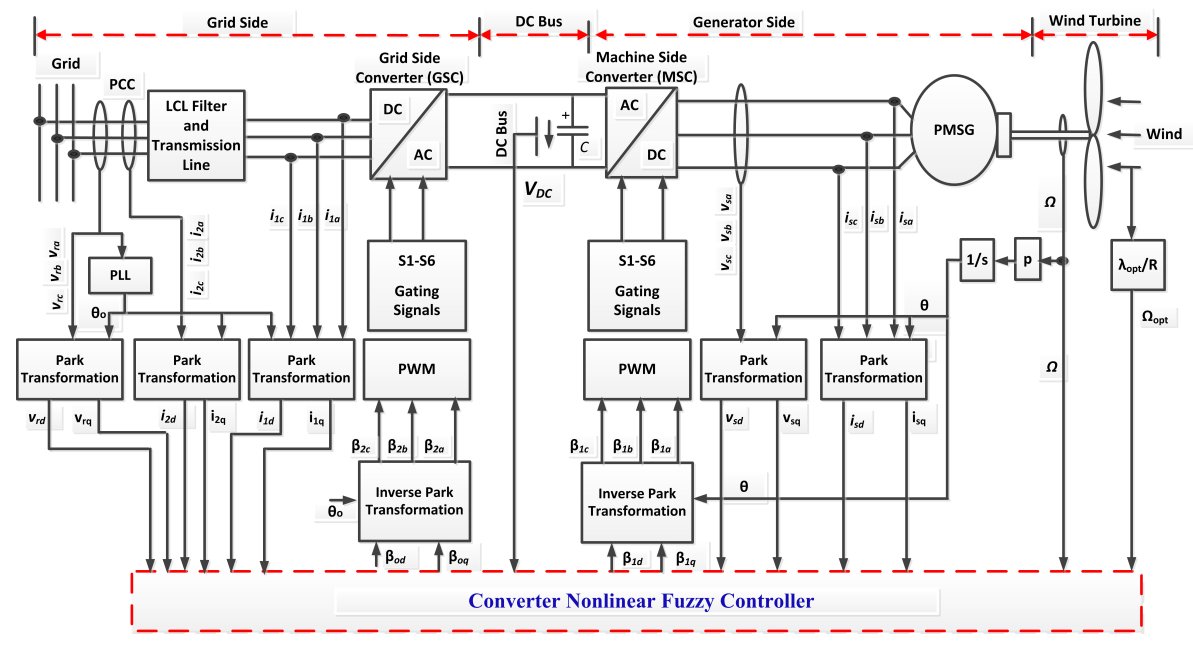

Fig. 2. Structure of the PMSG-WES with proposed control strategy.

$$
\begin{aligned}
\dot{X}(t) & =\sum_{i=1}^{p} \mu_{i}(q(t))\left[\bar{A}_{i} X(t)+\bar{B}_{i} u(t)+\bar{D}_{w i} \bar{w}\right] \\
Y(t) & =\sum_{i=1}^{p} \mu_{i}(q(t)) \bar{C}_{i} X(t)
\end{aligned}
$$

where, $X(t)=\left[\begin{array}{ll}x(t) & \xi_{i}\end{array}\right]^{T}, x(t) \in \Re^{n \times 1}, y(t) \in \Re^{g \times 1}$ and $u(t) \in \Re^{m \times 1}$ are the state, the output and the input vectors, respectively, $C_{i} \in \Re^{g \times n}$ is the system output matrix, $A_{i} \in$ $\Re^{n \times n}$ and $B_{i} \in \Re^{n \times m}$ are the system matrix and input matrix, respectively, $p$ is the number of TS fuzzy model rules. In order to force to zero the steady-state tracking error, we add a new state which corresponds to the integral of the tracking error $\epsilon$ $(i=1,2)$ by defining $\xi_{i}=\int_{T} \epsilon_{i} d t$ with $\epsilon_{i}=y_{l}-y_{i, r e f}$, where $y_{i, r e f}=\left[\begin{array}{ll}V_{D C(r e f)} & \Omega_{o p t}\end{array}\right]^{T}$

\section{B. Proposed Converter Nonlinear Fuzzy Algorithm Design and Stability Analysis}

1) Converter Nonlinear Fuzzy Algorithm Strategy Principle Design: In this section, the proposed strategy is developed based on Parallel Distributed Compensation (PDC) [4]. Sufficient conditions for the existence of CNFC is given in terms of LMIs. The final output of the proposed strategy is given as the following

$$
u(t)=-\sum_{j=1}^{p} \mu_{j} K_{j} X(t)
$$

where $K_{j}$ are the controller gains.

2) Stability and Robustness Analysis: The main result for the global asymptotic stability of a TS fuzzy model is summarized by the following Theorem.

Theorem : The equilibrium of the fuzzy control system as given by (4) subject to disturbances is asymptotically stable in the whole domain by the controller (5), if the controller gains are set to $K_{i}=O_{i} Q_{i}^{-1}$, and there exists a positive definite symmetric matrix $P_{i}=Q_{i}^{-1}$ and scalars $\gamma$, such that the following LMIs formulation for $H_{\infty}$ are satisfied,

$$
\min _{O_{i}, Q_{i}} \gamma
$$

such that,

$$
\begin{gathered}
{\left[\begin{array}{ccc}
\bar{A}_{i} Q_{i}+Q_{i} \bar{A}_{i}^{T}-\left(\bar{B}_{i} O_{i}\right)-\left(\bar{B}_{i} O_{i}\right)^{T} & Q_{i} \bar{C}_{e i}^{T} & \bar{D}_{w i} Q_{i} \\
\bar{C} Q_{i} & -I_{1} & 0 \\
Q_{i} \bar{D}_{w i}^{T} & 0 & -\gamma^{2} I_{4}
\end{array}\right] \leq 0} \\
Q_{i} \geq 0
\end{gathered}
$$

Proof. In order to carry out the analysis, the augmented fuzzy control system should be obtained first. To LMI formulation for $H_{\infty}$ performance, we denote the influence of $\bar{w}$ on the tracking error $\epsilon_{i}$ by the Root Mean Square (RMS) gain $\left(H_{\infty}\right.$ norm) for the the closed loop system as:

$$
\|T\|=\sup _{\|\bar{w}\|_{2} \neq 0} \frac{\left\|\xi_{i}\right\|}{\|\bar{w}\|_{2}}
$$

Now, suppose there exists a quadratic Lyapunov function $V(X(t))=X(t)^{T} P X(t)$ with $P=P^{T} \geq 0$, such that,

$$
V(X(T))+\int_{0}^{T}\left(\xi_{i}^{T} \xi_{i}-\gamma^{2} \bar{w}^{T} \bar{w}\right) d t \leq 0
$$

since $V(x(T)) \geq 0$, this implies

$$
\frac{\left\|\xi_{i}\right\|_{2}}{\|\bar{w}\|_{2}} \leq \gamma
$$

From (10), the derivative of quadratic Lyapunov function can be written and we obtain the following BMI

$$
\left[\begin{array}{cc}
\left(\bar{A}_{i}-\bar{B}_{i} K_{i}\right)^{T} P+ & P\left(\bar{A}_{i}-\bar{B}_{i} K_{i}\right)+\bar{C}_{e i}^{T} \bar{C}_{e i} \\
\bar{D}_{w i}^{T} P & P \bar{D}_{w i} \\
& -\gamma^{2} I_{4}
\end{array}\right] \leq 0
$$

From (12) and using the Schur lemma, LMI (7) is obtained. The Converter Nonlinear Fuzzy Controller (CNFC) gains ( $K_{i}=O_{i} Q_{i}^{-1}$ ) are calculated by solving LMIs (6)-(8). 


\section{Simulation STUdiES}

To check the PMSG-WES model and the performances o the proposed overall control, Matlab simulation and discus sions on the model proposed in Section II are presented. Th same proposed strategy is designed for transmission line o length $l=500 \mathrm{~km}$ is tested in two cases. In the first cas $\epsilon$ the proposed strategy is validated at the nominal condition with the transmission line length $l=500 \mathrm{~km}$ with differen wind velocity variations. In the second case the same propose controller is tested with the grid faults with varying the length of the line of network between $N_{2}$ and $N_{3}(l=10 \mathrm{~km} \mathrm{t}$ $l=2000 \mathrm{~km}$ ), to find the robustness margin of the propose method.

\section{A. Simulation 1: Overall Control Architecture Validation at Nominal Conditions}

In this simulation, the behaviour of closed loops is simulated at the nominal conditions (i.e., with controller synthesized for the exact length of the line $(l=500 \mathrm{~km}$.) and without strong disturbance like the short-circuits). The wind speed profile is shown in Fig. 3 (uper). One of the main objectives is to design a good tracking control scheme which is able to drive mechanical rotation speed to follow its optimal reference $\left(\Omega_{o p t}=\frac{\lambda_{o p t} v}{R}\right)$ (cf. Fig. 3 (lower)) to maximize the wind turbine power, where $R$ is the rotor radius, $\lambda_{o p t}$ is the optimal tip-speed ratio, $v$ is the wind velocity. In addition, DC-Link voltage is controlled such that it follows its reference $V_{D C}$ (ref) as shown in Fig. 4 (uper). Simulation results of the grid voltage $\left(v_{r}\right)$ is given in Fig. 4 (lower).
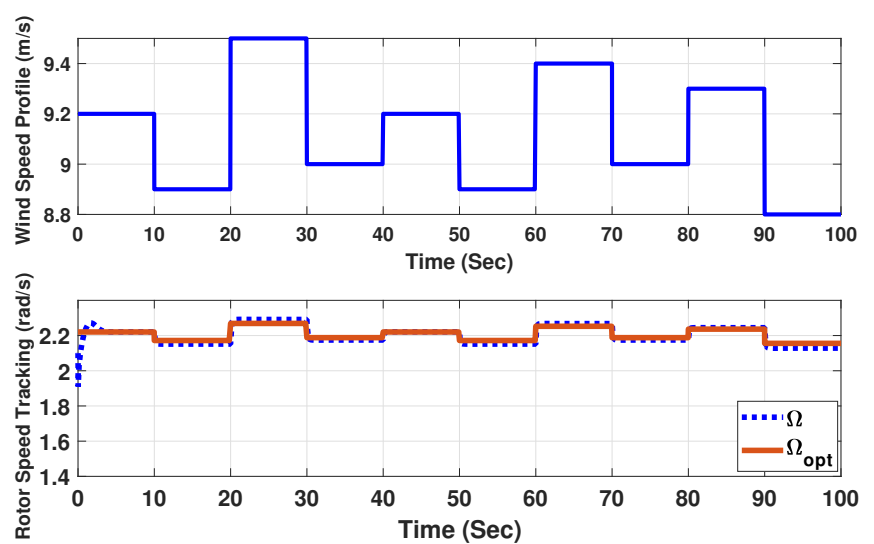

Fig. 3. Wind speed variation $(v)$ (uper) and Rotor speed tracking $(\Omega)$ (lower)

The simulation 1 results have shown the correct behavior of the proposed strategy applied on each component in the whole system which is proposed in Section II.

\section{B. Simulation 2: Overall Control Architecture Validation with Long Transmission Line Length and the Grid Faults}

One of the objectives of this work is to design robust controller to improve the steady-state and transient stabilities of the PMSG connected to an infinite bus in terms of shortcircuit system dynamics. The same nominal proposed strategy, which is designed for transmission line of length $l=500 \mathrm{~km}$
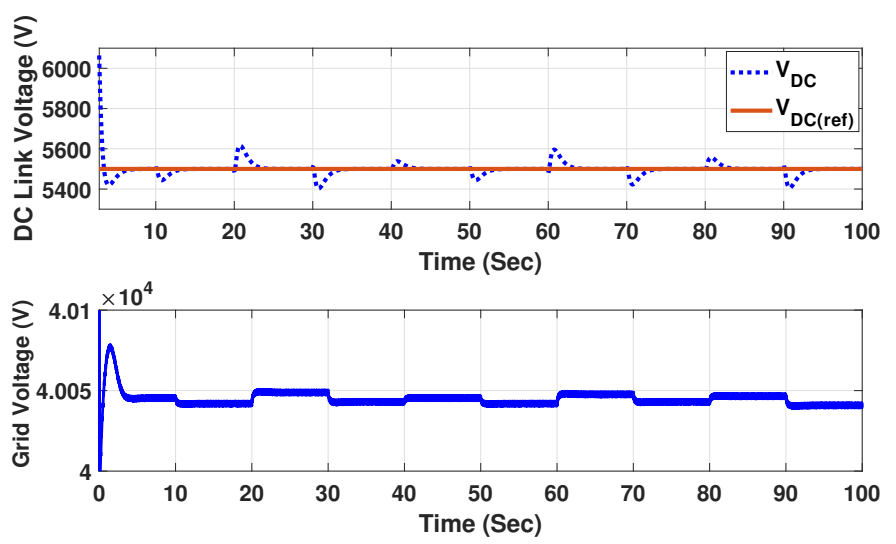

Fig. 4. DC-Link voltage tracking $\left(V_{D C}\right)$ (uper) and grid voltage $\left(v_{r}\right)$ (lower).

is validated with constant wind variations, grid fault conditions and varying the length of the line of network between $N_{2}$ and $N_{3}$ from $l=10 \mathrm{~km}$ to $l=2000 \mathrm{~km}$. The network fault is applied at $t_{s}=20$ during $150 \mathrm{~ms}$. The three phases of the line between $N_{2}$ and $N_{3}$ are grounded during $\Delta t=150 \mathrm{~ms}$. In this case $Z_{g}$ is divided into parts $Z_{g}=Z_{g 1}+Z_{g 2}$, where $Z_{g 1}=\alpha Z_{g}$ and $Z_{g 2}=(1-\alpha) Z_{g}, \alpha$ is the short-circuit distance of the AC line between $N_{2}$ and $N_{3}$. The grid voltages $\left(v_{r d}\right.$ and $\left.v_{r q}\right)(13)$ are given by

$$
v_{r d}=\alpha Z_{g} i_{2 q}, \quad v_{r q}=\alpha Z_{g} i_{2 d}
$$

and $V=0$ in this case. Different network situations are simulated by varying the lengths of the line of network between $N_{2}$ and $N_{3}$ (from $l=10 \mathrm{~km}$ to $l=2000 \mathrm{~km}$ ). Fig. 5 shows the response of the grid voltage $\left(v_{r}\right)$ (bus $N_{1}$ ). Figures 6 and 7 show the responses of the other variables of the DCLink voltage tracking $\left(V_{D C}\right)$ and rotor speed tracking $(\Omega)$ to the same situation.

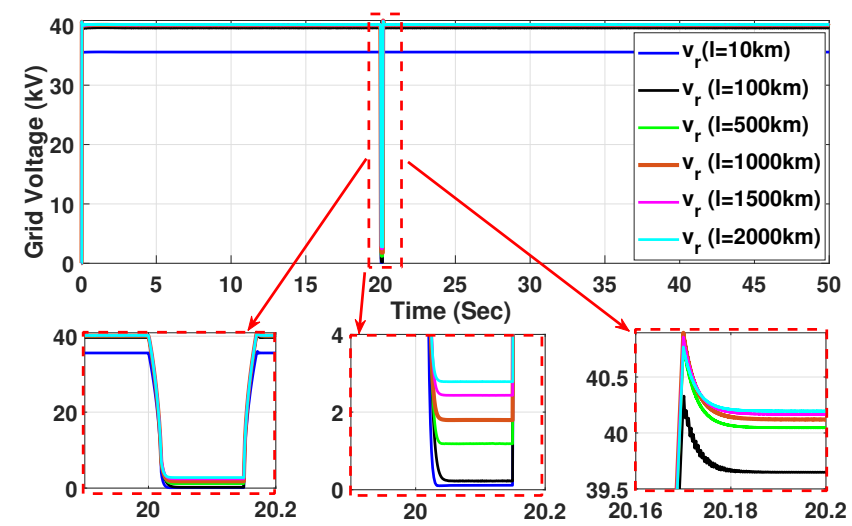

Fig. 5. Simulation results of the grid voltage $\left(v_{r}\right)$ in the presence of a network fault, for a length of the line between $N_{2}$ and $N_{3}$ from $l=10 \mathrm{~km}$ to $l=$ $2000 \mathrm{~km}$ (uper), zoom on grid voltage (lower).

From the simulation 2 studies, it can be seen that the gains of the proposed strategy which correspond to $l=500 \mathrm{~km}$ cover all the grid connection situations with satisfactory performances. The same CNFC strategy (same controller and 


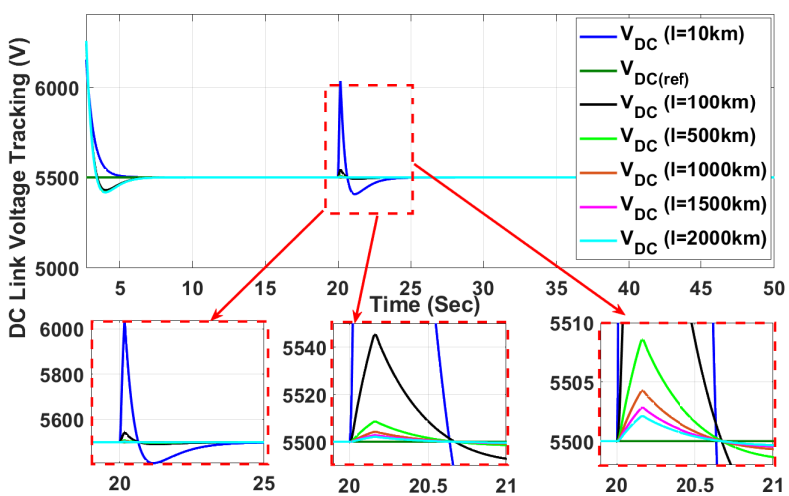

Fig. 6. DC-Link voltage tracking $\left(V_{D C}\right)$ in the presence of a network fault, for a length of the line between $N_{2}$ and $N_{3}$ from $l=10 \mathrm{~km}$ to $l=2000 \mathrm{~km}$ (uper), zoom on DC-Link voltage tracking (lower).

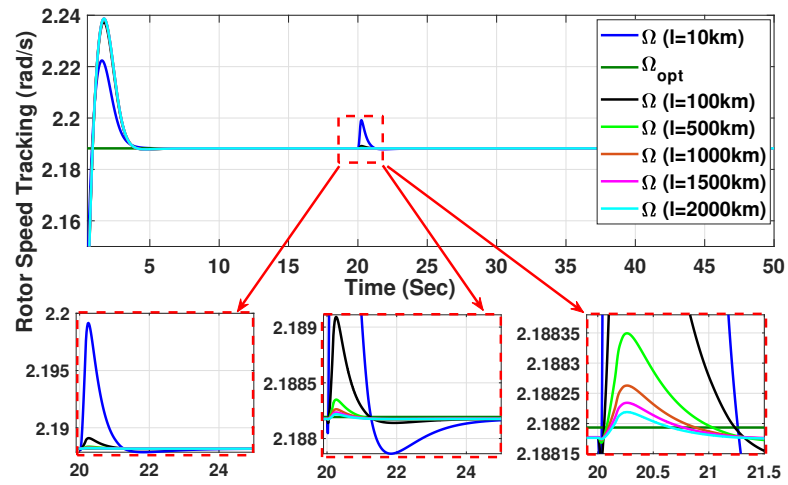

Fig. 7. Rotor speed tracking $(\Omega)$ in the presence of a network fault, for a length of the line between $N_{2}$ and $N_{3}$ from $l=10 \mathrm{~km}$ to $l=2000 \mathrm{~km}$ (uper), zoom on rotor speed tracking (lower).

same parameters) is used to test for line length from $l=10 \mathrm{~km}$ to $l=2000 \mathrm{~km}$ with the grid fault conditions. Compared to controller given in [16], the proposed strategy is stable over a much wider range of grid impedance more than 10 times at the same grid fault conditions test.

\section{CONCLUSION}

The control approach of the wind system with the PMSG connected to a real network has been presented in this paper. This approach allows the control of the DC-Link voltage of the DC and rotor speed. The synthesis of the proposed controller is based on the modeling of the machine connected to an infinite bus through an equivalent line. The CNFC is designed based on TS fuzzy model and PDC. Sufficient conditions for robust stabilization of the TS fuzzy model were derived in a LMIs formalism. The closed loop behavior of system is improved especially in case of network short circuits and thus make possible the connection of the PMSG to a network with variable short-circuit impedance. The approach provides the following major advantages: (i) Both MSC and GSC converters are controlled by CNFC; ii) a new global approach for the control of a variable speed wind system based on PMSG; iii) Tthe two back to back converters are controlled in a coordinated manner and this allows for better operation in the event of a network failure; iv) The network parameters in which the PMSG is connected are taken into account for the controller synthesis; (v) Fault Ride-Through Capability (FRT) capability is improved and validated by CNFC; (vi) It is stable over a much wider range of grid impedance more than 10 times compared with linear quadratic method (LQ) in [16] at the same grid fault conditions test.

\section{REFERENCES}

[1] M. Nicholas and E. M. Paul, Facts On Grid Friendly Wind Plants, Proceedings of PES2010, vol.8, no. 3, pp. 1-7, 2010.

[2] H. Geng, L. Liu and R. Li, Synchronization and Reactive Current Support of PMSG-Based Wind Farm During Severe Grid Fault, IEEE Trans. Sustain. Energy, vol. 9, no. 4, pp.1596-1604, 2018.

[3] M. Bejaoui, I. Slama-Belkhodja, E., Monmasson, B. Marinescu and L. Charaabi, FPGA design of a robust phase locked loop algorithm for a three phase PWM grid connected converter, Power Electronics and Applications, EPE'09, Barcelona Spain, pp. 1-10, 2009.

[4] E. Kamal and A. Aitouche, Robust scheduler fuzzy controller of DFIG wind energy systems, IEEE Trans. Sustain. Energy, vol. 4, no. 3, pp. 706-715, 2013

[5] N. K. Poulsen, T. J. Larsen, and M. H. Hansen, Comparison Between a PI and LQ-Regulation for a 2 MW Wind Turbine, Ris $\emptyset$ National Laboratory, 2005.

[6] M. Liu, J. Zou, C. Peng and Y. Xie, M. Li, Active Power Control for Wind Farms Based on MPC Combined with State Classification, IFAC PapersOnLine, vol. 50, no.1, pp. 2137-2144, 2017.

[7] S. Boersma, V. Rostampour, B. Doekemeijer, J.-W. van Wi ngerden and T. Keviczky, Model Predictive Wind Farm Controllerwith Linear ParameterVarying Models,IFAC PapersOnLine, vol. 51, no.20, pp. 241-246, 2018.

[8] L. Qiao and Y. Yang, Improved results on stability analysis and controller synthesis for T-S fuzzy systems, International Journal of Systems Science, vol. 49, no. 12, pp.2670-2681, 2018.

[9] E. Kamal and L. Adouane, Hierarchical Energy Optimization Strategy and its Integrated Reliable Battery Fault Management for Hydraulic-Electric Hybrid Vehicle, IEEE Transactions on Vehicular Technology,, vol. 67, no. 5, pp. 3740-3754, 2018.

[10] E. Kamal, A. Aitouche, and D. Abbes. Robust fuzzy scheduler fault tolerant control of wind energy systems subject to sensor and actuator faults, International Journal of Electrical Power and Energy Systems, vol. 55, no.1, pp. 402-419, 2014

[11] E. Kamal, A. Aitouche. Fuzzy Fault-Tolerant Control of Wind-Diesel Hybrid Systems Subject to Sensor Faults, IEEE Transactions on Sustainable Energy, vol. 4, no 4, pp. 857-866, 2013.

[12] E. Kamal, A. Aitouche, R. Ghorbani and M. Bayart. Robust Nonlinear Control of Wind Energy Conversion Systems, International Journal of Electrical Power and Energy Systems, 44, no.1, pp. 202-209, Jan. 2013.

[13] E.Kamal, A. Aitouche, R. Ghorbani and M. Bayart. Robust Fuzzy Fault Tolerant Control of Wind Energy Conversion Systems Subject to Sensor Faults, IEEE Transactions on Sustainable Energy, vol. 3, no 2, pp. 231$241,2012$.

[14] E. Kamal and A. Aitouche, Robust fault tolerant control of DFIG wind energy systems with unknown inputs, Renewable Energy, vol.56, pp. 2$15,2013$.

[15] M. Bejaoui, B. Marinescu, I. Slama-Belkodja and E. Monmasson, Control of DFIG for wind energy in a network context: a new formulation and interpretation of the control specifications, Proc. IEEE PES Innovative Smart Grid Technology, Manchester-UK, 5-7 December, pp. 1-7, 2011.

[16] M. Bejaoui, B. Marinescu, I. Slama-belkhodja and E.Monmasson, Control of doubly-fed induction generator for wind energy in network context, IET Renew. Power Gener., pp. 1-10, 2013.

[17] M. Bejaoui, B. Marinescu, I. Slama-Belkodja and E. Monmasson, Control of DFIG for wind energy in a network context: a new formulation and interpretation of the control specifications, Proc. IEEE PES Innovative Smart Grid Technology, Manchester-UK, 5-7 December, pp. 1-7, 2011.

[18] E. Kamal, M. Koutb, A. A. Sobaih and B. Abozalam, An intelligent maximum power extraction algorithm for hybrid wind-diesel-storage system, Int. J. Electr. Power Energy Syst., vol. 32, no. 3, pp. 170-177, 2010.

[19] P. Kundur, Power system stability and control, New York: McGraw-Hill, 1994. 